\title{
Health Insurance and the Demand for Medical Care: a Case Study from China
}

\section{Zi-Yi Guo}

'Corporate Model Risk Group, Wells Fargo Bank, N.A., Charlotte, NC, USA

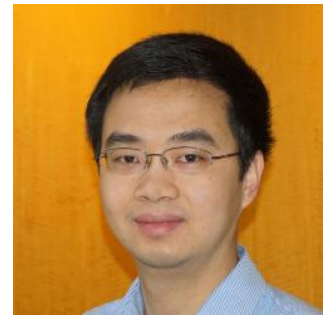

\begin{abstract}
Standard insurance theory expects that expenditures and coverage should be positively correlated, for two main reasons: first, high risky individuals prefer to choose a more generous coverage (selection effect); second, a more extensive coverage may increase health costs (incentive effect). We try to empirically separate the selection effect and incentive effect on the health care expenditures with a novel Chinese dataset. With our estimation, we do find the evidences of selection effect, but fail to find the incentive effect. Besides, we also find some evidences of Physician-Induced Demand.
\end{abstract}

Keywords: Selection effect, Incentive effect, Physician-induced demand.

\section{JEL Classification: C2 1, I1 1, I13.}

Citation | Zi-Yi Guo (2017). Health Insurance and the Demand for Medical Care: a Case Study from China. Asian Journal of Economics and Empirical Research, 4(1): 8-13.

History:

Received: 24 March 2017

Revised: 6 April 2017

Accepted: 12 April 2017

Published: 5 May 2017

Licensed: This work is licensed under a Creative Commons

Attribution 3.0 License (cc))

Publisher: Asian Online Journal Publishing Group

\section{Contents}

1. Introduction

2. The Chinese Health Insurance System

3. Data

4. The Model Estimation and Results

5. Conclusion

Funding: This study received no specific financial support

Competing Interests: The author declares that there are no conflicts of interests regarding the publication of this paper.

Transparency: The author confirms that the manuscript is an honest, accurate, and transparent account of the study was reported; that no vital features of the study have been omitted; and that any discrepancies from the study as planned have been explained.

Ethical: This study follows all ethical practices during writing.

References 


\section{Introduction}

Health care industry, which consumes over 10 percent of gross domestic product of most developed nations, has become one of the world's largest and fastest-growing industries. For United States, the health care expenditure accounted for $13.9 \%$ percent of gross domestic product (GDP) in 2001, and reached to 17.1 percent of GDP in 2014.1. A well-known explanation of this rapid increase has emphasized the spread of health insurance, since it has generated demand for both a higher quality and an increased quantity of medical services (Feldstein, $1971 ; 1977)$.

Standard insurance theory expects that expenditures and coverage should be positively correlated, for two main reasons. First, individuals who anticipate high health care costs may choose a more generous coverage (selection effect). Second, a more extensive coverage might demand more health costs (incentive effect), either through an increase in the probability to undergo sickness (ex ante moral hazard) or through an increase in expenditures in a given health state (ex post moral hazard). Even if these two explanations are theoretically different for the causality relationship between costs and coverage, they are quite difficult estimated separately, especially on cross sectional data (see, e.g. Chiappori and Salanie (2000)). Nevertheless, there are some studies focusing on solving the selection versus incentive effects puzzle. The Rand Health Insurance Experiment (RHIE) in 1974 conducted a randomized experiment to estimate how demand responds to changes in price of health care (Manning, 1998). Some natural experiments were also exploited, such as in Chiappori and Salanie (2000). Finally several studies simultaneously estimate the demand for health care and the demand for insurance to identify both effects. Some other recent studies include: Cohen and Siegelman (2010); Chandra and Skinner (2012); Einav et al. (2013); Nardi et al. (2016) and Keane and Stavrunova (2016). Here, I want to study the selection versus incentive effects puzzle by using a novel Chinese data set.

In China, historical reasons, "Hukou", have separated rural area residents - farmers - from social health insurance system provided by the government. The low level of development in the insurance industry also prohibits them to buy commercial health insurance. At the same time, people who work in the urban area, especially in the government sector, have social health insurance, which is required to be provided by the employers. From this point of view, one may consider occupations as a natural instrumental variable of insurance selection after controlled some variables. Meanwhile, people with some special occupations who live in the urban area are not protected by social health insurance and have the option to buy commercial health care insurance. Therefore, this group of people serves for a good candidate to study the self-selection effects.

Manning et al. (1987) write a seminal paper in this topic. Manning et al. employ the data from a randomized experiment and estimate how cost sharing, the portion of the bill the patient pays, affects the demand for medical services. A catastrophic insurance plan reduces expenditures 31 percent relative to zero out-of-pocket prices. The price elasticity is approximately -0.2. Their results reject the hypothesis that less favorable coverage of outpatient services increases total expenditures (for example, by deterring preventive care or inducing hospitalization). Gardiol et al. (2005) provide an analysis of the health insurance and health care consumption. They develop a structural microeconomic model of joint demand for health care and health insurance and estimate the model by the full maximum likelihood (MLE) method using Swiss insurance claims data for over 60,000 adult individuals. Their empirical analysis illustrates robust and strong evidence of selection effects. While once selection effects are controlled for, a significant incentive effect ("ex-post moral hazard") remains. The marginal demand for health care decrease from $100 \%$ to $0 \%$ by about $90 \%$ was induced by a decrease in the copayment rate from $100 \%$ to $10 \%$. The correlation between health care expenditures and insurance coverage may be decomposed into the two effects: $25 \%$ may be attributed to incentive effects, and $75 \%$ to selection effects.

In this paper, I revisit the problem why there is a positive correlation between health insurance policy and health care expenditures and investigate the selection effects and the incentive effects by using a novel Chinese data. In our sample estimation, we confirm the positive correlation between health insurance policy and health care expenditures. However, after we try to separate the selection effect and the incentive effect from the positive correlation, we can only find the evidence of selection effect, but fail to find the incentive effect. There are increasing interests about the health care expenditures in China, such as Lei and Lin (2009); Xu and Yang (2009); Yip and Hsiao (2009a;2009b) and Ramesh et al. (2014). My paper studies the Chinese health care expenditures from a different perspective by focusing on comparison of the selection effect and the incentive effect.

The paper is organized as follow. Section 2 presents the Chinese health insurance system. In section 3, I will describe the data and explain the instrumental variable which I use. Section 4 will present the main empirical estimations and results. Section 5 concludes.

\section{The Chinese Health Insurance System}

This part mainly comes from the Annual Report (2002)2, and aims to introduce the Chinese Health Insurance System and shed light on the reasons why we select the instrument variables in the empirical studies. Since my dataset is from 2002, I will focus on the system during that year. With historical reasons, medical insurance in China has been segmented into two structures, one for urban employees and one for rural citizens with the health and retirement system structure as one of the administrative tools.

\subsection{Urban Health Insurance}

In December 1998, the Decision of the State Council on Establishing the Urban Employees' Basic Medical Insurance System was issued. This decision marked the beginning of a new attempt at developing a new social health care system in urban China since the old system is massively obsolete after the introduction of market reforms in the early 1980s. The old insurance system offered those covered people free health care in government run facilities. It had two-tiers, one covering the State Owned Enterprise employees and the other one covering military personnel, academics, social workers and the disabled. In contrast, the newly introduced urban system has 
only one tier in which participation is planned to be mandatory to all employees in both public and private companies, with the exception of the self-employed. However, instead of being free to those covered people, the new system employs a cost-sharing structure in which the government, employers and employees share the costs of health care. The employer contribution is 6 percent of total wages and the employee contribution is 2 percent of their wages, although local flexibility allows for some sway in contributions. Local governments are then responsible for the management of two funds, a general medical trust fund, used mostly to pay for in hospital services, and an individual employee accounts fund. All of the employee contributions and 30 percent of the employer contributions are put into the individual employee accounts fund while the remaining 70 percent of the employer contributions is collected into the general fund. However, the new system is only for those covered people, and non-employed urban residents, with a few exceptions, must still rely on commercial health insurance or individually pay all the medical costs.

Unlike the old system which would subsidize healthcare costs of the dependents of workers who are covered by medical insurance by 50 percent, dependents are not covered at all by the new system. However, retired and laid-off workers are covered by the new system. Re-employment centers pay laid-off workers by at a level of 60 per cent of the preceding year's local workers' average wage to be allocated following the same scheme as employed workers, sponsored by both the employee and employer contributions. The system covers retirees at no cost to them, but the legislation does not explicitly explain who bears their medical costs nor who contributes to their individual accounts, only citing that "the proportion of the amount of money charged into individual accounts of retirees and the medical expenses borne by individuals will be given appropriate preferential consideration," which most likely allows the issue flexible and let local authorities to decide. Otherwise, non-employed residents are not covered by any social health insurance coverage.

The new system allows local governments the ability to negotiate with any health-care providers (including private) over terms, coverage, and reimbursement of services, separating government- run hospitals from health insurance, although the vast majorities ( 88 percent) of hospitals remain not-for-profit. Since social health insurance no longer includes government healthcare institutions, a new form of distributing funds was also introduced. Under the national plan distributions largely handled by the locality, but some national guidelines were created as cost cutting measures. These included: a ceiling on expenditures from the general fund of four times the local average yearly wage; a requirement for localities to create copayment system which determines minimum out-ofpocket payments; and a formulary of permitted prescription drugs (in general 5-10 percent of cost). According to the law, local governments are required to divide permitted drugs into classes which are then reimbursed at different levels. For instance, Hunan Province built a structure which includes 25 percent of drugs in a "Class A" and 75 per cent of drugs into a "Class B", which are 70 percent and 63 percent respectively paid by the social health insurance system.

\subsection{Rural Health Insurance}

In the past, the rural healthcare system in China has actually witnessed great success, increasing the average life expectancy from 40 years in 1965 to 69 years in 1982. This belongs to the establishment of "barefoot doctors" in rural regions, who were community members receiving basic training from the government and could provide basic primary care for with low cost to the community. Secondary care, pharmaceutical drugs, and inpatient care had a coinsurance cost, but were much less than the price these services became after the market reforms. Since the old socialist cooperative health care system was not innovated and its funds fell to 15 percent of operating costs, the situation became more serious after market-reforms, forcing hospitals and doctors alike to fend for them in a privatized environment. To meet operating costs non-profit hospitals turned to selling expensive treatments which would be unnecessary for the patients. Over-treatment is estimated to have reached over 60 percent of medical costs and 75 percent of drug prescriptions were considered to be unnecessary, meaning patients were paying inflated amounts for even basic problems that used to be free to treat. In 2000 over 87 percent of sick people in rural areas paid their own medical expenses in full, and 25 percent had to borrow in order to cover the costs (also see the survey in the Annual Report (2002)).

Basically, we can see the coverage of health insurance is geographically segmented into two parts. With the severe Household Registration System, it is very hard for individual to officially change their jobs. Even if they find jobs in urban, they are still treated as residents from rural areas. Therefore, we could think health insurance policy is an exogenous variable for individuals, except few urban residents with special occupations.

\section{Data}

Our dataset is from the Beijing Shijitan Hospital (used to be Beijing Railway Hospital). The hospital is a marginal A-level hospital in Beijing. There are two main reasons why we choose this hospital. First, the hospital is a very typical one in Beijing. It is not very prestigious compared some hospitals in Beijing with national reputations. Therefore, we could expect almost all the patients are from Beijing local, not other provinces, since if patients from other provinces want to pay such a huge fixed cost to travel to Beijing for better medical care, they will be more likely to choose a better hospital with national reputations, such as Xiehe, because the restrictive regulatory in health care prices has made the differences of prices across hospitals very small. Second, relative to other provinces, Beijing is geographically very small. Therefore, we could assume urban area and the rural area in Beijing are quite similar, across a variety of variables, such as household income, environmental condition and so on. This dataset provides all the hospitalization patients' expenditures in the hospital in 2002 with 13,506 observations in total. The dataset has the patients' information, including patients' ID; health care expenditures; health states before entering the hospital; health states after leaving the hospital; occupations; ages; gender; how many times have they been in the hospital because of this sickness; how many days they have stayed in the hospital; which section they have stayed in the hospital, total 11 variables.

Overall, the quality of the data set is pretty good. We delete one of the observations, whose health care expenditure is almost twenty times of the second largest one. Also, there are around 127 observations with missing data. Since they are quite randomly distributed, we delete them as well. After these implementations, we have 
13,278 observations in total. Since the health care expenditures are quite left skewed, we use log operation. After that, it is quite symmetrically distributed, but it is still not a normal distribution. We use Kolmogorov-Smirnov test to test is normality and it rejects at any kind of levels. In total, we have 62 occupations in the sample. Since we are only interested in whether the individuals are from rural area, we focus on these two, farmers and manual workers. We create two dummy variables, which denote farmers and manual workers respectively. There are two different health states before entering the hospital: emergency and regular. We also create one dummy variable for emergency. Some patients are very lucky to receive total recovery after the treatment; some patients become better, but not totally recover; some stay the same; unfortunately some even died in the hospital; and some others, unclear, may move to another hospital. We create four dummy variables for them except the regular one - recovery.

The summary statistics is as following in Table 1. As we can see, in the whole sample almost half of the patients have insurance and almost 20 percents of the population are from rural area. Seventeen percents of the patients are employee, which is a quite a huge number. My interpretation for the reason why it is so large is that perhaps some patients are the employees' relatives and ask them to pay for them and give the money back to the employees. We also check the insurance distribution for each occupation. Except farmers and manual workers, they are quite close. Almost each occupation has around 60 percents insurance coverage.

Table-1. Descriptive statistics of the variables

\begin{tabular}{|c|c|c|}
\hline Variable & Mean & Std. Dev. \\
\hline Expenditure & 7223.2 & 12809.9 \\
\hline Times & 3.917 & 4.949 \\
\hline Age & 45.432 & 21.482 \\
\hline Days & 19.578 & 32.777 \\
\hline Gender & 0.570 & 0.495 \\
\hline Employee & 0.174 & 0.194 \\
\hline Emergency & 0.168 & 0.322 \\
\hline Better & 0.272 & 0.283 \\
\hline No- recovery & 0.023 & 0.149 \\
\hline Death & 0.033 & 0.178 \\
\hline Others & 0.031 & 0.173 \\
\hline Insurance & 0.533 & 0.455 \\
\hline Farmer & 0.130 & 0.197 \\
\hline Manual & 0.051 & 0.061 \\
\hline
\end{tabular}

Source: Author calculation based on the data from Beijing Shijitan Hospital

\section{The Model Estimation and Results}

The Self-selection problem is a very widely discussed problem in econometrics. The paper will employ the "Heckman" selection model, which is analyzed in Heckman (1979) a widely-used modeling choice in microeconometrics.

To set up the self-selection issue, assume that we wish to estimate parameters $\beta$ of the regression:

$$
\mathrm{Y}_{\mathrm{i}}=\mathrm{X}_{\mathrm{i}} \beta+\epsilon_{\mathrm{i}}
$$

for a population of individuals. In eq. (1), $\mathrm{Y}_{\mathrm{i}}$ is the dependent variable, which is individual's expenditure on health care. The variables explaining outcomes are $\mathrm{X}_{\mathrm{i}}$, and the error term is $\epsilon_{\mathrm{i}}$. $\mathrm{X}_{\mathrm{i}}$ includes a variety of explanatory variables, such as income, age, gender, insurance type, and so on. Since individuals with bad health states have an incentive to increase their insurance consumptions, the problem of endogeneity comes out. The control function: $\mathrm{I} \beta_{\mathrm{i}}=1\{\mathrm{Z} \gamma+\mathrm{V} \geq 0\}$

Since we suspect insurance will be an endogenous variable, to fully identify $\beta$ one has to appeal to IV methodology. Here we choose farmers and manual workers as two instrumental variables. I will explain why these two variables should be valid instruments in next paragraph.

As I introduced in the section about the Chinese Health Insurance System, historical reasons has separated the China into two segmented parts: rural area and urban area. The Household Registration System has almost made the impossibility for people to move from rural areas to urban areas. To acquire to urban area registration, people usually should pay a huge cost except through finding a job in government sector. Especially in Beijing, the cost in 2002 is around 200,000 RMB. To win a job in government sector, it is usually very competitive and only a small portion of people who are very well educated can have that chance. China only reforms its education system in 2000. Before 2000, the entrance rate of college is below than 2 percents. Even there exists a selection issue for jobs, we should expect the correlation between selection in jobs and selection in insurance policy should be very small. As I mentioned, Beijing is very geographically small. Actually, the difference between its rural area and its urban area is quite small, in a variety of context, such as household income and environment. One even can say its rural areas are just nominally named rural areas, while they actually are "urban area." Therefore, we can conclude there is no much difference in nature between people from its rural areas and people from its urban areas.

At first we run a reduced form regression as follows.

$$
\begin{aligned}
\text { insurance }= & .3862+.0028 \text { times }+.0037 \text { age }+.0001 \text { days }+.0301 \text { emerg } \\
& +.1658 \text { gender }+.7444 \text { employee }+.0127 \text { better-.0258norecovery } \\
& -.0190 \text { death-.0230others-.5588farmers- } .3149 \text { manual }+\varepsilon
\end{aligned}
$$

Except health states when leaving (including better, no-recovery and death), all other variable are significant at $5 \%$ significance level. So we can see both farmers and manual are negatively related with insurance policy. Both farmers and manual workers have less access to insurance policy. The F-value of the joint test of the two coefficients is 290 and its p-value is around zero. Since we have two instruments, to check their validity, we also 
run the over-identification test. The value of Sargan (score) test is: $\operatorname{chi} 2(1)=2.31773(\mathrm{p}=0.1279)$, so one cannot reject the over-identification hypothesis. This gives us an indirect evidence of the validity of our instrumental variables.

At first, we will run a pooled a regression to see without instrumental variables, how will be the results.

$$
\begin{aligned}
\log (\text { expenditure })= & 7.288516+.0108 \text { times }+.0133 \text { age }+.0115 \text { days } \\
& -.2048 \text { emerg }+.0792 \text { gender-.1690employee }+.0640 \text { better } \\
& -.2094 \text { norecovery }+.4475 \text { death-.7646others }+.2517 \text { insurance }+\varepsilon
\end{aligned}
$$

All the coefficients are significant at $5 \%$ level. As one can see, without instrumental variable, people who have insurance will significantly increase their health care expenditure, by $25.17 \%$, more than one quarter. To see whether the positive correlation is because of selection effect or incentive effect, we run the two-stage least square regression.

$$
\begin{aligned}
\log (\text { expenditure })= & 7.351+.0113 \text { times }+.0140 \text { age }+.0115 \text { days- } .1995 \text { emerg } \\
& +.1088 \text { gender- } .2925 \text { employee }+.0662 \text { better- } .2141 \text { norecovery } \\
& +.4448 \text { death-.7703others }+.0829 \text { insurance }+\varepsilon
\end{aligned}
$$

The t-value of the coefficient of insurance becomes 0.59 , which means we cannot reject the null hypothesis. Therefore, after we control the selection effect, we cannot find evidence of positive correlation between insurance and health care expenditure. Basically, we cannot find incentive effect in our sample estimation, including either ex ante moral hazard or ex post moral hazard.

Another interesting finding in our estimation is that the coefficient of employee is negative and significant. Our interpretation is that since employees have better information than regular patients, the asymmetric information between physician side and patient side becomes much smaller, so we can see the physician-induced-demand effect reduces by significantly. As mentioned in the Handbook chapter by McGuire (2000) there is empirical support for physician-induced demand. The three mechanisms physicians may use to influence quantity of care provided to patients are: quantity setting of a non-retradable service, influencing demand by setting the level of noncontractible input ("quality"), and, in an asymmetric-information context, taking an action to influence patient preferences. With limit of data, we cannot check the effect separately, but we can make our argument: physicianinduced demand effect is significant in our sample estimation.

\section{Conclusion}

In the paper, we revisit the problem why there is a positive correlation between health insurance policy and health care expenditures by using a novel Chinese data. In our sample estimation, we confirm the positive correlation. However, after we try to separate the selection effect and the incentive effect from the positive correlation, we can only find the evidence of selection effect, while failed to find the incentive effect.

There are several directions for future research. First, the dataset is not based on a randomized experiment. Since we use occupation as an instrumental variables, as we know occupation is strongly correlated with individual incomes, if we can find individual incomes in occupation level, the estimation will become much more convincing. Second, although we think our instrumental variables are valid ones, they are still controversial. People might differ in occupation level. Intuitively, some occupations have some risky elements. However, we cannot control them with our data set. If one cannot find very good instruments, partial identification approach as in Manski (1993) and invalid IV as in Hahn and Hausman (2005) approach might be good substitutes. Finally, the paper does not have a structural model to support its empirical estimation. If one cannot construct a solid structural model, it would be very interesting.

\section{References}

Annual Report, 2002. Ministry of Health of the People's Republic of China. Available from http://www.moh.gov.cn/publicfiles//business/htmlfiles/wsb/index.htm.

Chandra, A. and J. Skinner, 2012. Technology growth and expenditure growth in health care. Journal of Economic Literature, 50(3): 645680. View at Google Scholar

Chiappori, P. and B. Salanie, 2000. Testing for asymmetric information in insurance markets. Journal of Political Economy, 108(1): 56-79. View at Google Scholar | View at Publisher

Cohen, A. and P. Siegelman, 2010. Testing for adverse selection in insurance markets. Journal of Risk and Insurance, 77(1): 39-84. View at Google Scholar | View at Publisher

Einav, L., A. Finkelstein, S. Ryan, P. Schrimpf and M. Cullen, 2013. Selection on moral hazard in health insurance. American Economic Review, 103(1): 178-2 19. View at Google Scholar

Feldstein, M., 1971. Hospital cost inflation: A study of nonprofit price dynamics. American Economic Review, 61(5): 853-872. View at Google Scholar

Feldstein, M., 1977. Quality change and the demand for hospital care. Econometrica 45(7): 1681-1702. View at Google Scholar $\mid$ View at Publisher

Gardiol, L., P. Geoffard and C. Grandchamp, 2005. Separating selection and incentive effects in health insurance. Paris-Joudan Sciences Economiques, Working Paper.

Hahn, J. and J. Hausman, 2005. Estimation with valid and invalid instruments. Annals of Economics and Statistics, 79(2): 25-57. View at Google Scholar | View at Publisher

Heckman, J., 1979. Sample selection bias as a specification error. Econometrica, 47(1): 153-161. View at Google Scholar |View at Publisher

Keane, M. and O. Stavrunova, 2016. Adverse selection, moral hazard and the demand for medigap insurance. Journal of Econometrics, 190(1): 62-78. View at Google Scholar | View at Publisher

Lei, X. and W. Lin, 2009. The new cooperative medical scheme in rural China: Does more coverage mean more service and better health? Health Economics, $18(\mathrm{~S} 2)$ : S25- S46. View at Google Scholar |View at Publisher

Manning, W., 1998. The logged dependent variable, heteroscedasticity, and the retransformation problem. Journal of Health Economics, 17(3): 283-295. View at Google Scholar | View at Publisher

Manning, W., J. Newhouse, N. Duan, E. Keeler, A. Leibowitz and M. Marquis, 1987. Health insurance and the demand for medical care: Evidence from a randomized experiment. American Economic Revie, 77(5): 251-277. View at Google Scholar 
Manski, C., 1993. Identification of endogenous social effects: The reflection problem. Review of Economic Studies, 60(3): 531-542. View at Google Scholar View at Publisher

McGuire, T., 2000. Physician agency. Handbook of health economics. Edited by A.J. Culyer and J.P. Newhouse. Elsevier Science B.V, 1., Chapter 9: The Netherlands: Amsterdam. pp: 461-536.

Nardi, M.D., E. French and J. Jones, 2016. Medicaid insurance in old age. American Economic Review, 106(5): 3480-3520. View at Google Scholar

Ramesh, M., X. Wu and A. He, 2014. Health governance and healthcare reforms in China. Health Policy and Planning, 29(1): 663-672. View at Google Scholar

Xu, J. and Y. Yang, 2009. Traditional Chinese medicine in the Chinese health care system. Health Policy, 90(3): 133-139. View at Google Scholar 1 View at Publisher

Yip, W. and W. Hsiao, 2009a. China's health care reform: A tentative assessment. China Economic Review, 20(1): 613-619.

Yip, W. and W. Hsiao, 2009b. The Chinese health system at a crossroads. Health Affairs, 27(2): 123-142. 